\title{
INDIGENOUS AND SCIENTIFIC KNOWLEDGE IN THE FARMING SYSTEM: A CASE OF URBAN AGRICULTURE IN KAGESHWORI-MANOHARA MUNICIPALITY
}

\author{
Kanhaiya Sapkota*
}

\begin{abstract}
This study aims to analyse some contradictions and the interface between scientific and local knowledge on urban agriculture based on the one hundred and five households survey in KangeshworiManohara low-lying Area. Semi-structure questionnaires interviews, key informant survey, field observations as well as categorization techniques were used for both qualitative and quantitative data and information. The farmers had changed their production from traditional to intensive, market-oriented agriculture. The transition had made tem to adopt wider range of improved farming techniques that means the by and large had entered into economically viable production, and also sustainable in terms of nutrient balance. The farmers' practices had indicated some extent of link between scientific and indigenous knowledge.
\end{abstract}

Key words: Urban agriculture, indigenous/local knowledge, scientific knowledge, farming system, social perspective, economic perspective, ecological perspective.

\section{INTRODUCTION AND OBJECTIVE}

Agricultural development strategies to date were chiefly based on Western technological solutions, with mixed success rates. Farming Systems Research (FSR) was advanced as a way to increase the use of indigenous knowledge of farming to make new technologies more adaptable and appropriate to farming conditions. Farming System Research has enabled researchers to focus attention on people and their knowledge by increasing people's participation in problem identification and new technology validation (Lumu et al., 2013). In practice, though, FSR continues to be a top-down approach: technologies continue to be developed (in most cases) in the exogenous, Western knowledge system. Little has been done to develop

* Mr. Sapkota is an Associate Professor, Central Department of Geography, Kirtipur, TU. 
indigenous technology generating and diffusing capacities already present in the rural areas (Blaikie \& Brookfield, 1987). However, urban agriculture can be defined shortly as the growing of plants and the raising of animals within and around cities. The most striking feature of urban agriculture, which distinguishes it from rural agriculture, is that it is integrated into the urban economic and ecological system: urban agriculture is embedded in -and interacting with- the urban ecosystem (Yasmeen, 2001). Such linkages include the use of urban residents as labourers, use of typical urban resources (like organic waste as compost and urban wastewater for irrigation), direct links with urban consumers, direct impacts on urban ecology (positive and negative), being part of the urban food system, competing for land with other urban functions, being influenced by urban policies and plans, etc. Urban agriculture is not a relic of the past that will fade away nor brought to the city by rural immigrants that will lose their rural habits over time. It is an integral part of the urban system (Blaikie \& Brookfield, 1987; Sapkota, 2003b). Therefore, it refers to farming nearby the cities, generally intensive semi or fully commercial production, which is becoming a permanent pattern of urban land use. Growing urban population and their demands for food and other agricultural products will also have some major impacts on land use in urban areas (Lumu et al., 2013).

Urban agriculture has been practiced from the very beginning in Nepal and the farmers of this zone operate under different sets of conditions and choices (Sapkota, 2003a). Not all products are consumed in the household. For the farmers who sell all or part of their produce, market access is an important factor and most of the agricultural products are determined by urban demands (Sapkota, 2003b). Moreover, because of proximity to the agricultural input sources, means of communication, transport as well as labour and market in the urban areas, agriculture becomes modernised rapidly.

Recent interest in the value of farmers' indigenous knowledge in less developed countries like Nepal has largely stemmed from dissatisfaction with diffusionist and modernization approaches in dealing with poverty, a situation exacerbated by the seeming inability of science and technology to improve living standards significantly for the majority of people in less developed countries (Blaikie \& Brookfield, 1987). Consequently, there is considerable interest in understanding indigenous knowledge in less developed countries, and how this might be incorporated into development discourses. It is also now being increasingly realized that the combined 
use of local knowledge and modern technology provide a sound basis for promoting the productivity use of local resources and in enhancing the sustainable management of the resources (Sapkota, 2003c, Bhatta, 2011). The aim of this paper is to highlight on issues relating to existing links between local knowledge and modern technology (scientific knowledge) in the context of sustainable urban agriculture in Nepal. However, the local knowledge is the term often used today to recognize a form of knowledge, which is holistic, and orally transmitted within local communities, whereas according to Scoones and Thompson (1993), the scientific knowledge is seen as theoretically based and that can be generalised as well as propositional knowledge.

The local knowledge is also a valuable and under-utilised resource, because it transforms the traditional practices to the new generation. In reality, social and cultural values are the major sources of local knowledge. On the basis of epistemic and ontological discourses, the rational science is assumed and the quests of change is derived almost completely from the findings of the research stations and transmit to the farmers through either adopters or rejecters of technologies (Scoones \& Thompson, 1993; Lumu et al., 2013). In western philosophical traditions, the treatment of other forms of knowledge (i.e. local knowledge) is rather quite different and that tend to define anything else that does not qualify as western as backward, primitive and unscientific. Nevertheless, according to Warren (1991), local knowledge is unique to a given culture or society. Similarly, Gupta (1987) argues that the local knowledge is culturally constituted and ideologically shaped arena of meaning, which provides both the terms of reference and the means of expression, which motive the actions of social agents. In this respect, in farming system, farmers developed knowledge of agronomy to production decision. The terms, in which they formulated, presented and justified their agricultural decisions. It indicates that local agricultural knowledge and technology or scientific knowledge is important element in the agricultural production process of local people (Lumu et al., 2013). Local knowledge is seen as knowledge, which is holistic, because it treats the farming systems or farming practice as an interdependent part of the whole environment, nature and its diversity. However, the "western" approach is called scientific one, which may be considered reductionism, focusing on yields of a particular crop only and perhaps even causing crisis to nature in the long run where conversion of multi-purpose husbandry to single-purpose takes place and pollution of groundwater and diseases are 
caused by fertilizers and pesticides. In the process of modernisation, scientific knowledge is regarded as superior at technical innovation, development and rapid transformation than the local knowledge (Briggs, 2005). It indicates the domination of science over the local knowledge, but people have trust in their local knowledge. However, in reality the situation is different because no knowledge starts by being scientific. Most of what constitute scientific knowledge was once local, and some scientific knowledge has a propensity to become local at some stages. It indicates no any knowledge is superior or inferior, thus, we can claim that any particular form of knowledge is always believable in relation to its own practitioners (Briggs, 2005).

\section{REVIEW OF LITERATURE}

The concept of development as modernisation emerged in 1960s (Hettne, 1990). In the landmark of modernisation of agriculture, two major themes have dominated (Pretty, 1995). One has been the need for increased food production to meet the need of a growing population in the world. For the achievement of this agricultural modernisation landmark, governments have taken initiation and intervene to transform traditional agricultural systems by encouraging the adoption of modern varieties of crops and livestock together with associated packages of external inputs necessary to increase production. Similarly, the governments also take an initiation and support for new technologies (machinery), infrastructures (irrigation, road, markets), as well as introduce different agricultural policies to encourage changing their traditional farming systems to modernisation. The second most important theme of the modernisation process is to prevent the degradation of natural resources. For the protection of natural resources, governments have shown concern and encouraged adoption of soil and water conservation measures to control soil erosion. Pretty has also argued that it would appear that agricultural development has been remarkably successful in these respects.

However, since 1945, modernisation theory has dominated the development discourses, which aimed at dealing with poverty through the application and transfer of science and technology as understood in the developed countries (Briggs, Badir \& Mekki 1999; Lumu et al., 2013). Thus, poverty is to be eradicated through the diffusion of such formal scientific and technological knowledge, and hence development is framed as largely a technical issue, strongly influenced by the science discourse currently dominant in the European and North American countries. 
However, agricultural development in Nepal, as in most other developing regions, has concentrated on the transfer of high input technology from the North. Traditional agriculture system, which is the product of centuries of accumulated experiences of peasant farmers, are considered incapable of boosting productivity to feed the country's rapidly growing population (Briggs, 2005).

Food production and land conservation have significantly increased in the world due to the modernisation process in agriculture. The main assumption of this modernisation process is that technologies are universal. During the Green Revolution of the 1960s and onwards, it was widely believed by scientists that they would be able to transform agricultural systems without affecting the social formation. This landmark of modernisation has often led to the adoption of new technologies and practices, which is a rather contradictory for the farmers because most of the farmers have different socio-economic and environmental conditions, needs and values as well as constraints to use modern technologies in the agriculture. That means, yet not all farmers wish to adopt all modern technologies (innovations), nor are all technologies suitable to all agricultural lands. Then, farmers reject the type of technologies that does not fit to their needs or is too risky to use (Pretty, 1995; Sapkota, 2003a; Briggs, 2005). However, urban areas are indirectly affected by the achievement of Green Revolution. Due to the proximity to urban centres, the impact of modern technology transformation regarding agriculture has occurred very rapidly in the, urban areas. In this respect, due to the packages of external inputs, urban agriculture has also been rapidly transformed towards modernisation. Nevertheless, the technology transfer does not have sophistication. Central to this is the notion that the new technologies are better than those from the past are, so represent 'progress' (Pretty, 1995; Briggs, 2005; Lumu et al., 2013).

The major part of the process of modernisation of agriculture is the financial incentives i.e. subsidised fertilizers, pesticides and credits to the farmers. Nevertheless, the impact of Green Revolution or modernisation takes place some erosion of diversity in agricultural practices. The main assumption of modernisation of agriculture is better standardisation of agriculture. Farmers are economic, rational and they change their own livelihoods, simplifying their practices to incorporate new technologies. Such approaches or technologies lead to homogenisation of their agricultural activities. Before the Green Revolution or the modernisation of agriculture, farmers grew more crop varieties. Similarly, they grew some 
specific plants for home made pesticides and insecticides, but now they are depending upon the industries and the market economy. However, there has developed a growing dissatisfaction with the contribution of perspectives to understanding and dealing with poverty, reflected by increasingly critical reappraisals of the role played by scientific and technological knowledge as an engine of modernisation. In particular, their general ineffectiveness in significantly improving the living standard of the majority of the world population over the last 40-50 years (Blaikie \& Brookfield, 1987).

Thus, there has been a recent reframing of the debate with calls to explore alternatives to modernisation as a theory and practice of development. Important sign points in this debate include a critique by Chambers (1983), in which attention was drawn to the ways in which the framing of 'development' resulted in various inappropriate outcomes, in the sense that for majority of the people of rural areas, development strategies and projects have been for the large part inappropriate or even irrelevant. However, it is not totally clear whether the farmers used their own knowledge systems as the basis for successful agricultural production as knowledge complementary to scientific knowledge, offering a more powerful and relevant development strategy that is more in tune with the needs and priorities of the people affected.

Currently, there appears to be some tension between contributions of indigenous knowledge and scientific knowledge (formal science). Although this work has been supported and developed by further theoretical and empirical works, alternative perspectives to modernisation, including indigenous knowledge, have been slow to develop and even slower to the accepted (Bebbington, 1993 in Briggs, Badir \& Mekki, 1999); Lumu et al., 2013). Maddox, Giblin \& Kimambo (1996) successfully captured this in their conceptualisation through two different viewpoints: narratives mostly dominate one over indigenous knowledge operating in harmony with nature, whilst the next one suggests a condition of hostile, threatening environments, a condition that, of course, can only be successfully treated by the application of capital and technology. Both views, however, seriously underestimate the capacity for constructive transformation from within rural communities themselves; both, to a greater or lesser extent, are dismissive of the utility of indigenous knowledge (Briggs, Pulford, Badir, \& Shaheen, 1998; Bhatta, 2011). 
This paper aims to investigate the ways in which urban farmers of the Kageshwori-Manohara area are taking decisions about the choice of crops and the agricultural techniques for cultivation and subsequent management of soils.

\section{STUDY AREA}

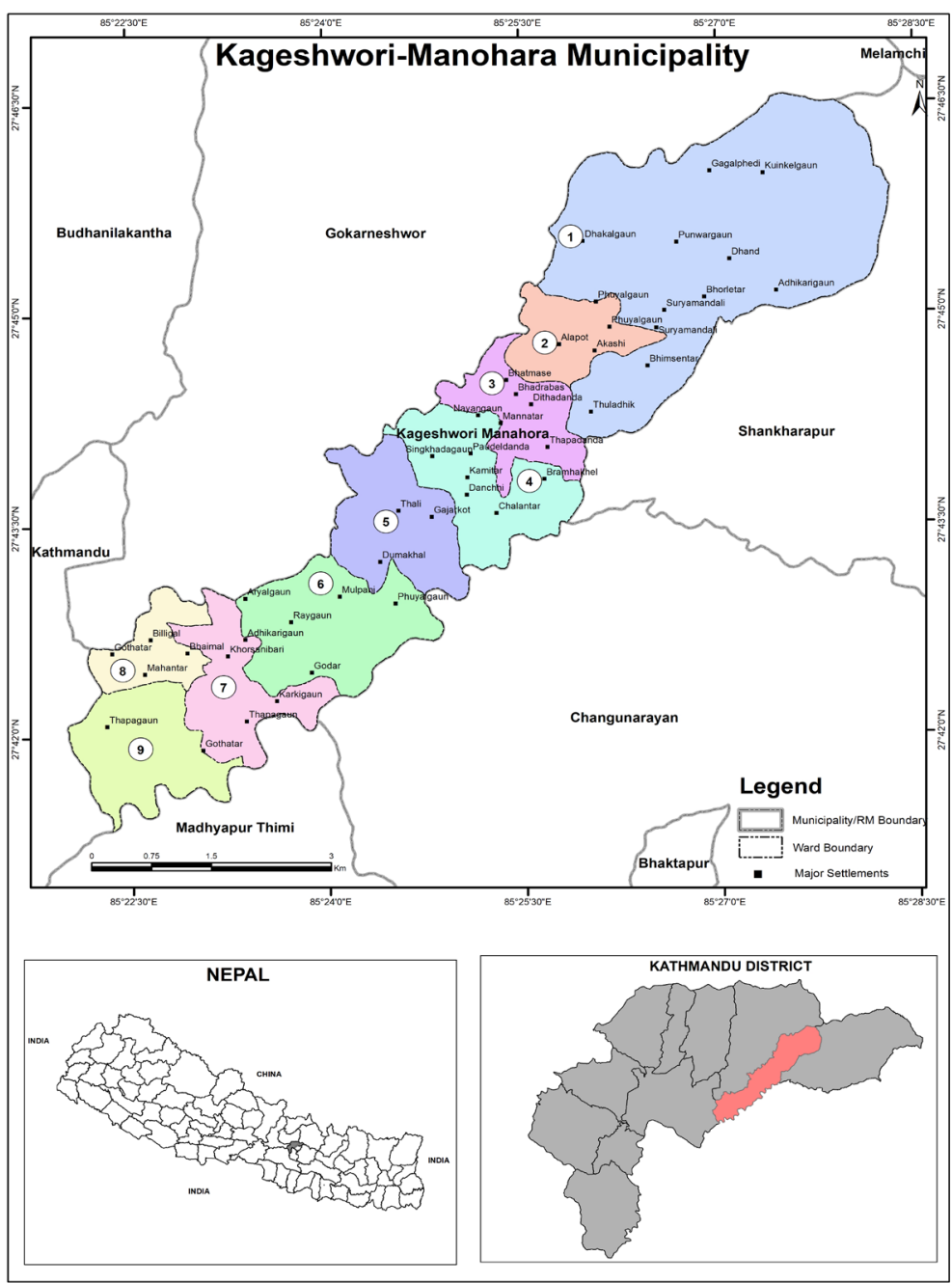

Kageshwori-Manohara, low-lying area of Kathmandu district, which lies in the northern part of Kathmandu valley. Kageshwori Manohara Municipality was declared on Mangsir 16, 2071 B.S. consisting of 16 wards. It was formed merging the then VDCs viz: Gothatar, Mulpani, Danchi, 
Bhadrabas, Aalapot and Gagalphedi. Total population of this municipality is 60247 (Male: 30021 and Female: 30226). The total households of this VDC is 14340 as well as the literacy rate is 80.9. The municipality is covered 27.38 sq.kms area. This study area has been selected for many reasons: firstly, this is a typical land where agriculture has been intensively practiced. In terms of production, this location is the good and suitable for the all-seasonal crops. Secondly, the traditional irrigation system is still preserved but not sufficient for rice production, and the intensive horticulture is the main characteristics of this area. This is the area near by the major market centres, and it is the main source of perishable vegetables for the urban dwellers, that is the other reason. The local farmer can easily transport their requirements associated with the agriculture practice, i.e. agricultural tools, fertilizers, pesticides, for better production. The good transportation facilities, which permits transport of perishable vegetable products to the urban centre and also other part of the city, is another reason for the selection of this area. The area is located at about $1300 \mathrm{~m}$ elevation and falls within the warm temperate belt. During the winter season, night frost may occur, but the climate permits year round cropping.

The climate is dominated by the south-east monsoon rains, which approach from the Bay of Bengal. These rains cause about 80 percent of the annual precipitation to occur from June-September. The rainfall is heaviest from the second half of June to the first half of September, with a considerable annual variation in the total number of rainy days.

The soil in general is medium to light textured as well as strongly acidic soil reaction, and represent low to medium soil fertility as indicated by low organic matter. However, the available nitrogen, phosphorous, and potassium are medium to very high in the soil. More or less this area is situated in the alluvial plain, which has some undulating surfaces. In the study area, farmers dig up a clayey sediment layer popularly known as Kalimati (Black soil) and use it as soil nutrients. There has been a great degree of specialisation in horticulture in the study area.

\section{METHODOLOGY}

There are a considerable theoretical debate about the links of indigenous and scientific knowledge as well as understanding urban farming and its management. However, is been rather less on appropriate methods for testing out such knowledge, although there are notable expectations such as observations and categorisation, emic and etic approaches, and work. A 
survey of urban agriculture in Kageshwori-Manohara low-lying area was undertaken using a checklist-questionnaire and to gain information about the best general locations of preferred cultivation sites, which was based on the field works on 105 households survey. The households had been selected from those wards which were dominated by the agricultural activities (i.e. ward 1, 4, 5, 6, 7 and 9) based on the cadastral map, agricultural plots have been selected and it traces out the land owners through the municipality record. From the households survey, general households level information, application of modern agricultural extensions as well as their traditional knowledge which they were practiced since very long time in their area had been explored.

Observations of categories was an important method in the research, which was ascribed from the local knowledge. Nevertheless, there are different cultures of different groups of people in different parts of the world. Due to this variation the different culture localises the observations into different categories and then produce different meaning. Categories are not only differentiated by culture but also by profession, gender and generations within same culture (Aase, 1997). Thus, different people might have different categories and perceived different meanings. To understand the local knowledge and their perceptions, the use of agricultural inputs, there is need of using method of observations; talk with the local key informants farmers and through semi-structured interviews.

Moreover, preliminary interviews with key informants (i.e. ward chairperson, senior citizens, agrovet shopkeepers) who had broader ideas in general were undertaken to gain an overview of the local perceptions of how the urban agricultural system was being managed. Key informants were usually the first informants, they often possess the expertise to liaise between me, and the communities being researched (Hay, 2000). Key informants are 'culturally qualified', so their review could be useful litmus for the test of interview design. During fieldwork this they were requested six key informants (from the different walk of life) to share their knowledge and perception about the use of indigenous and scientific knowledge in their existing agricultural activities. The source of primary data is based on a structured and semi-structured (content focused) interviewing with sample households, preliminary or exploratory field observations, subjective assessment and contacting key informants and resource persons. Besides that, several discussions were also made with the local key informants, and collected relevant information through semi-structured interviewing technique. During the fieldwork, the researcher had constantly considered 
the ethical implications and critical reflexivity. Being reflexive means analysing situation of the self. In other words, the researcher was fully conscious about the process of constant, self-conscious, scrutiny of the self as researcher and of the research process.

Here, Rappaport's (1967) argument for the separate analysis of 'cognised' and 'operational' models can be immensely helpful. He argues that people in any culture interact with the natural world in terms of their own meanings or knowledge, which may have no relation with the scientific explanations. It is very important to understand how people create and maintain this 'cognised' model of the universe. At the same time, it is important for us to understand this interaction from an 'outsider's perspective' which help us to understand the relationship between the local knowledge and its correlation with the scientific explanations. In other words, the etic and emic approaches help to understand how people understand and analyse their resources and methods, and to what extent they are similar to the knowledge developed in the field of technical studies.

\section{RESULT AND DISCUSSION}

Urban agriculture in Kathmandu was seemed to be threatened because of the rapid urbanization and high rate of population growth. Peoples were migrating from various parts of the country for better life, good education, and employment opportunities to the urban areas. Due to this, land value was also skyrocketing, farmers have now started to sell their lands at high prices, which encouraged the fragmentation of agricultural land, and it changed into the residential or permanent fallow land. A new generation of young people are starting to divert from agriculture to other activities. They prefered business or other income generating activities. Although, regarding the urban agriculture system in the study area, it was still gaining the impressive achievements in very tough competition with the others. Nevertheless, there were some problems regarding the intervention of government institutions, because it was necessary to intervene for the scientific knowledge transfer to the local farmers. Due to the lack of extension support, they were not able to produce as much as expected.

\section{Soil Fertility Status}

The dominant views expressed was that although the soils was of high quality, it was fragile and in need of careful management. Soil fertility and nutrient management influence agricultural productivity. Maintaining soil fertility was an important step in creating a sustainable agriculture, which was important for the development of urban agriculture. In this 
area, farmers were practicing different methods (scientific and local) for soil fertility management. They were applying both organic and inorganic fertilizers. Benefits of chemical fertilizers were low cost and easy to apply. Farmers were claiming that when chemical fertilizers and other pesticides were introduced, the production was increased and then they were gradually facing number of problems regarding the loss of soil quality. According to them soil turned into dry and harder as well as some of the vegetables which they traditionally cultivated was also not growing properly. Hence the soil fertility was gradually declining due to inadequate and imbalanced nutrient application and improper farming practices. Crop rotation is also applied. Different crops used and replenish different minerals. Crop rotation was not always economically feasible particularly in the case of urban agriculture system; because it was market oriented farming system and farmers depend on the urban demand. This means the need for fertilizer input, but it did not completely solve the problem. Some of the farmers had leave crop residues on the field after harvesting for erosion prevention, to retain moisture and enrich the soil. The minerals within the maize stalks and hay as well as other plants decompose was backed down into the soil and it had provided more organic matters for the soil.

According to Chaudhary and Manandhar (1996), Nepal's per hectare nutrient consumption is not only the lowest in Asia but also highly unbalanced in terms of N, P and K application. In the study area, N and P was dominating the supply. The cropping patterns did not incorporate legumes and other crops having nitrogen-fixing ability but were mostly based on market-oriented crops, which remove significant amounts of nutrients from the soil. The farmers had adopted improved varieties of seeds. Due to this fact, they were starting to give less attention and importance to the traditional source of nutrients (organic manures from various sources like FYM, green manure, crop residues), which had improved chemical and physical properties of soil. Farmers argued that even supply of chemical fertilizers was increasing, they were unable to maintain soil fertility, and yields were declining.

Here Rappaport's (1967) argument for the separate analyses of 'cognised' and 'operational' models is reflected, because we can categorise separate views based on local and scientific knowledge. It indicates that the importance of the interaction from an 'outsider's perspective' which can help us to understand the relationship between the local knowledge and its correlation with the scientific explanations. The farmers argued that fields were hoed one or two days before planting or sowing of seeds in the belief, 
that exposure to the sun had killed the weeds. However, in some cases, they left the weeds on the soil surface as protective mulch, to recycle nutrients and to allow nitrogen assimilation through the bacteria decomposing the plants. The crops could then develop fully. Similarly, they put some chicken manure with other compost manure during the field preparation or levelling the land for plantation. Manual weeding was carried out during the field preparation and any time they try to control weed on their farmland. Burning weed was also a traditional practice.

In the study area, the two basic types of soil fertility maintenance were manuring and management. Crop residues burned, ash added to the farmland, chicken and livestock manure spread on fields, leaf litter and night soil (in some cases) spread on their agricultural land. These had widely practiced in both Khet and Bari land. Based on local knowledge, local farmers had also used farmyard manure (FYM) for almost all vegetable plants. Manure was mixture of straw, cow dung, urine and other plant materials. According to them raw cow dung was not good for vegetable farming. Therefore, they had preferred FYM was for the farmland. They said FYM regulates the supply of nitrogen and changes the colour of the soil, which was essential for absorbing sunlight. To some extent farmers had burnt grasses before the rains to enhance fertility levels through the release of nutrients.

Table 1: Sum up of Soil Fertility Status

\begin{tabular}{|l|c|l|c|c|c|}
\hline Soil Property & $\begin{array}{l}\text { Mean } \\
(\mathbf{n = 1 0 5})\end{array}$ & Rating & $\begin{array}{l}\text { Standard } \\
\text { Deviation }\end{array}$ & . & \\
\hline $\mathrm{pH}$ & 4.68 & Strongly Acidic & 0.31 & 3.5 & 5.4 \\
Organic Matter (\%) & 2.26 & Low & 0.80 & 0.13 & 4.56 \\
Total N (\%) & 0.19 & Medium & 0.14 & 0.038 & 1.138 \\
Available P & 978.68 & Very High & 381.00 & 90 & 2179 \\
Exchangeable K & 310.24 & High & 138.60 & 96 & 749 \\
Boron & 0.0051 & Very Low & 0.0053 & 0.0 & 0.02 \\
Zinc (AAAC-EDTA) & 3.8062 & Medium & 2.0752 & 0.480 & 9.226 \\
\hline
\end{tabular}

Source: Field survey, 2017.

Note: $\mathrm{N}=$ Nitrogen, $\mathrm{P}=$ Phosphorous, $\mathrm{K}=$ Potassium, AAAC-EDTA = Acid Ammonium Acetate - Ethylenediaminetetracetic Acid Method 
The fact sheet of soil analysis indicates the status of soil nutrients of the study area. The overall scenario regarding the soil analysis had indicated that the levels of nutrients were not much problem except boron. Most soil $\mathrm{pH}$ values fall within 3.5 to 5.4 (extremely acidic to moderately acidic) was indicating $\mathrm{pH}$ to be more serious than reported from other middle areas, for instance, Jhiku Khola area (where the $\mathrm{pH}$ value was 4.94 in red soil and 4.78 in non-red soils (Schreier et.al 1994 in Shah, 1996). About twelve percent of the samples were very low-to-low in total N. A large variation in available P levels was evident; however, the levels were high to very high. About fifty-five percent of exchangeable $\mathrm{K}$ values was in the range of high to very high. Boron was completely deficit and in the case of $\mathrm{Zn}$, it is not much problem. Most of the farmers practiced intensive agriculture that allowed them to produce food and vegetables and manage plant diseases for some decades with few outside inputs. Many of their successful practices had been forgotten or abandoned in some cases of urban farmers and the rural farmers, but some were still used by traditional farming systems and managements in this area. A traditional farming system usually was based on practices that have been passed down for many generations. In the study area, still most of the farmers were using traditional way of farming system.

Before 10-15 years, most of the local farmers put night soil for the betterment of soil and for nutrient for the plants. They believed that the night soil was the main source of nutrients for the vegetables. Now, this practice was almost disappeared because of the availability of different industrial product nutrients (i.e. chemical fertilizers and micronutrients). According to them, when they used only FYM, organic manure and home made pesticides and insecticides, the quality of land was very good and the soil was in good and fertile condition. After the haphazard use of chemical fertilizers, they had only one complain that the quality of land has been degraded and faced the plant-damaging problems. They had still prefered to apply organic manure in the field, because of the high cost and the low quality of chemical fertilizers and other nutrients. 
156 INDIGENOUS AND SCIENTIFIC KNOWLEDGE IN THE FARMING ...

Table 2: Troubleshooting Chart for Compost Pile/heap (Summarised Output from Household Survey and KII)

\begin{tabular}{|l|l|l|}
\hline \multicolumn{1}{c|}{$\begin{array}{c}\text { Farmer's claim } \\
\text { regarding compost } \\
\text { preparation }\end{array}$} & $\begin{array}{c}\text { Problem of the } \\
\text { symptoms which } \\
\text { farmer's claim }\end{array}$ & $\begin{array}{c}\text { Suggestions from } \\
\text { Agricultural } \\
\text { Extension Office }\end{array}$ \\
\hline $\begin{array}{l}\text { The pile is damp and } \\
\text { good smelling, but still } \\
\text { not heat up. }\end{array}$ & Lack of nitrogen. & $\begin{array}{l}\text { Mix in a nitrogen } \\
\text { source such as manure }\end{array}$ \\
\hline $\begin{array}{l}\text { The compost pile is cold } \\
\text { and wet. }\end{array}$ & $\begin{array}{l}\text { Too much rain or } \\
\text { moisture. }\end{array}$ & $\begin{array}{l}\text { Cover with a mulch of } \\
\text { finished compost or a } \\
\text { tarp }\end{array}$ \\
\hline $\begin{array}{l}\text { The compost is damp } \\
\text { and warm only in the } \\
\text { middle. }\end{array}$ & $\begin{array}{l}\text { Compost pile is } \\
\text { too small. }\end{array}$ & $\begin{array}{l}\text { Collect more material } \\
\text { and mix it into the } \\
\text { existing pile }\end{array}$ \\
\hline $\begin{array}{l}\text { The pile attracts flies, } \\
\text { rodents, and pets, etc. }\end{array}$ & $\begin{array}{l}\text { Not mixed well. } \\
\text { have been added to } \\
\text { the pile. }\end{array}$ & $\begin{array}{l}\text { Do not add meat scraps. } \\
\text { Mix the pile and cover } \\
\text { with soil }\end{array}$ \\
\hline $\begin{array}{l}\text { The interior of the pile is } \\
\text { dry. }\end{array}$ & Not enough water. & Moisten and turn pile \\
\hline Has a bad odour. & $\begin{array}{l}\text { Aerate it. Add dry } \\
\text { material if the pile is } \\
\text { too wet }\end{array}$ \\
\hline
\end{tabular}

Source: Field survey, 2017.

The farmers were facing some problems regarding compost preparation, which was basically embedded in their traditional practices or knowledge. Compost is not properly decomposed due to several reasons. Most of the farmers were facing the above-mentioned problems. Nevertheless, during the study period the agricultural extension office provided some suggestions about how to solve the problem of compost preparation. Farmers who were having the problem of compost preparation and management yet to consult themselves to the extension officer and nobody had visited to extension office for the suggestions yet. However, they had shared their problems regarding the farming activities with each other (one farmer to another) and tried to settle down the problem by themselves. If they were not able to solve the problem, then consulted with the agro-vets (Table 2). 


\section{Trends of Use of Local vs Modern Inputs}

Labour force is the main pillar of the farming system. Local farmers had prefered to use family labour, but due insufficient family labour and the improvement of their economic status, they hire labour for the land preparation. After the introduction of chemical fertilizers, pesticides and insecticides, some of the women's works had been reduced but not noticeable change on the rhythm of every day life. Before that, women were working for the preparation of homemade pesticides/insecticides and even put on the farm as well as they involve into collection of different plants and other things for the preparation of organic manure. Now, they could easily buy the insecticides/pesticides as well as even organic manure in the market. Nevertheless, they had participated equally as before but the natures of job was slightly changed and concentrated in the other farm activities as well. The researcher asked questions about the difference between two chemical fertilizers commonly used at the time of sowing, urea and DAP (di-ammonium phosphate) with the farmers and they responded that:

DAP turns out to be better because at the time of sowing, it gives the seed enough heat (Takat/Shakti) for the plant - DAP does - that till the end the plant maintains itself well. Urea cannot manage to give as much. The DAP (Phosphates) gives it heat. It means DAP gives heat to the seeds and then the production is good. Similarly, they also told that "urea makes plant grow, DAP makes it sprout". To some extent, the local farmers had knowledge about the impact of the use of chemical fertilizers, If we put more fertilizer, plant will grow taller. When it grows tall and we irrigate it, there is a danger of the plant falling. If the standing paddy lodges, the production will be lower. So thinking this one can not put too much.

Decisions about which crops to grow in the field was directly tied to the availability and timing of inputs. Local farmers claimed that most and significant effect on the soil was excessive use of chemical fertilizer. In the interesting discourse of farmers, comparisons between manure (gobar ko $m \bar{a} l$ ) and chemical fertilizers (desi māl or rasaayanik māl or sarkari māl) loomed largely. While speaking of the strength of the soil, they inevitably pointed out the differences between manure and the chemical fertilizer and different kind of chemical fertilizers. Similarly, the farmers were attempted to make sense why they now needed larger amounts of chemical fertilizers than in the past. Most of the farmers replied that due to the degradation of the quality of soils (dry), they were using more and more chemical fertilizers 
than in the past. All the farmers thought that organic manure was better for the land than chemical fertilizers. According to them, manure released its heat/power (Takat/Shakti) slowly, whereas chemical fertilizers released their energy all at once.

There was an enormous quantity of power in cow dung (gobar $m \bar{a} l)$. No other has much power as gobar māl, not even urea. Similarly, gobar māl increases the growing strength (baliyo or majboot) of the land. It makes hard land soft and fertile. When the lands become fertile, the output or the production increases. If we put gobar $m \bar{a} l$ once, it effects last for several years. It doesn't dissolve all at once but the desi $m \bar{a} l$ dissolve all at once. These were the example of local knowledge, which some of the local farmers have. The farmers said that they were lazy because of the factory product fertilizers. There might be several reasons i.e. the lack of grazing land in the study area; the transportation cost has been increasing day-byday, not available on time because they were depending on the middlemen who bring different manures from outside. Whatever the reasons given by the farmers for the "lack" $(k \bar{a} m)$ of manure, they had become increasingly dependent on the use of chemical fertilizers.

When there is excess water, urea dissolves in it, goes underneath, and doesn't give its benefits to the crops and then it rains really hard. Suppose we put it now, and then if it does not rain for four to six hours, it is all right. A minimum of six hours needed for the plant to absorb the nutrients. If it rains immediately after the application, it will go to waste. The farmers were using a range of micronutrient mixtures as well as borax and boric acid, all referred to as 'vitamin' in the local terms, to increase agricultural productivity. They believed that the use of micronutrients was necessary because of the decrease in productivity caused by their use of huge amount of chemical fertilizers in the past. However, the local farmers did not have proper knowledge about how and which types of the micronutrients to use. They did not have crop or vegetable specific knowledge. They perceive that micronutrients were as vitamins; thus, they use any types of vitamin for their crops. However, they believed that the quality of fertilizers, pesticides and insecticides they buy from the local market were not good. They further believed that the qualities of these inputs was not good because most of them come from the neighbouring districts of India. Farmers even felt cheated because of the low-quality inputs, which they were bound to buy in the local area. Some of them find that the quality of soil is decreasing due the use of these inputs. Nevertheless, the local farmers did not believed 
those fertilizers, which were from India, because they previously used some Indian products and were not satisfied. They trusted on the products of Japanese, Indonesian, Bangladeshi. Thus, proper knowledge of nutrient availability and nutrient use efficiency not only helps to increase crop production but also to reduce the problem of environmental pollution by over fertilisation. Therefore, the soil fertility and the nutrient use efficiency of the crop plant were very important points to be considered for scientific plant nutrient management. Application of inorganic fertiliser is simply the addition of nutrients to the soil nutrient pool, necessary for crop production. It was the misuse of fertiliser or the use of them at the wrong rates and times that lead to environmental damage.

\section{Knowledge and Technology Transfers}

After 1970s, the view of technology transfer has consciously been focused on agriculture as an active partnership between rural people and agricultural extensionists (Scoones \& Thompson 1993). In this respect, outsiders play an important role to transfer and exchange of knowledge and ideas between farmers and others. Technological transfer and progress could help to produce more, safer, and higher quality food and agricultural products, at low cost as well as with lower depletion of the natural resource base. There is a risk that scientific technology or knowledge transfers developed as it may have been in 'laboratories' or at least isolated from existing local knowledge - fails to capture the unique relationship the farmers have with their own environmental and agricultural practices, - fails to capture the knowledge, and its framework which is handed down through generations. In theoretical contexts of agriculture, Pretty and Chambers (1993), criticise science is not build as a body of knowledge, principles and methods, but based on the beliefs, behaviour and attitudes that accompany it. Similarly, Marglin in 1992 (Hogg, 2000), goes further and suggests that modern science, because it portrays itself as the totality of knowledge, cannot peacefully co-exist with the tacit knowledge of farmers. Common to these perspectives is an appreciation, however varied, of the interplay between power and knowledge. The two are intimately bound and indeed one can postulate a dialectical interplay between the two. For Howes and Chambers (in Hogg, 2000), "scientists' need to lean on scientific knowledge to legitimise their superior status is at the roof of a bias against poly-culture systems" (Hogg, 2000). 
But, knowledge is not evenly distributed in the society. Different individuals are recognised as 'specialists' in particular fields and are central in the transmission of knowledge within a community or family. The knowledge transmission is not based on simple communication channels or linkages, which involves human agency and occurs within socially and politically constituted networks of different actors, organisation and institutions (Scoones \& Thompson, 1993). Local farmers argued that the government was not paying due attention to the urban agriculture. They had never met any extension worker working in the area. Some of them suggest that the state should provide them with some kind of assistance (i.e. credit without interest, subsidised chemical fertilizers, pesticides and insecticides, provide compost manure and give regular attention by the agricultural extension officers) in order to promote the quality and quantity of the agricultural products.

For the discussion about scientific knowledge transformation, we should mention the role of extension offices. Urban farmers have good access if they realise to make contact and get scientific knowledge from the different institutions. However, Nepal's agricultural research has historically harboured a misconception about what constitutes agricultural research (Blaikie \& Sadeque, 2000). In our context, Ministry of Agriculture is the main body of scientific knowledge transfer to the local level, which works through a network of extension officers (Andersen, 2000). The other main institution is NARC, which is an autonomous institution, has done number of research on agriculture systems in Nepal. In theory, NARC produces knowledge and the extension office transfer knowledge to the local farmers' level. Nevertheless, in reality knowledge is not really reaching to the farmers, because the recommendation, which NARC produced, was not formally providing to the implementation or extension offices. Thus, farmers were not getting proper information and knowledge as well as recent technological change, because they did not get regular monitoring and extension support from the office. The farmers did not realise that they had extension officers, and besides, the officers did often not provide appropriate information and advice to the local farmers. In the study area, none of the farmers interviewed had regular contact with the extension officers. Instead, the farmers received the information and knowledge from the agrovets and other farmers outside the study area. When the local farmers go to different market centres to sell their products, they discuss recent technological change and new inputs with each other. Farmers were 
using chemical fertilizers, which were available to the local agrovets, and the owners of agrovets spread the knowledge what he gets from the outsiders (the fertilizers and vitamins providers). They had exchanged their knowledge among each other through informal communication. Generally, the knowledge and technology transfer was based on the market-oriented mechanism. However, markets themselves did not develop new techniques or technologies, but helped to transfer knowledge and technology within the farmers and from institutions to the farmers. Farmers, who had access to the major market centres, were aware of the new technologies. The farmers of the study area were continuously looking for the affordable new technology and appropriate knowledge.

The rapid modernisation of agriculture and the introduction of new technologies such as those that characterised the improved seed varieties and the impact of Green Revolution have had a different impact on the local people. Shiva (1989) claims that the wealthy have benefited more from technological change in agriculture than the less well off and men have benefited more than women have. She also argues, women know that new scientific technologies disturb the rhythm of work and create more burdens and more risks. However there was not any disturbance and change in the rhythm of work related with the agriculture practices, because most of the women had same rhythm of work as men. They also had to some extent scientific knowledge and they were using it with their local knowledge system. Women's traditional agricultural work was not only integrated in the rhythm of the household, but also in the market economy. Thus, the local farmers who want to become more environments friendly had reduced inputs (modern inputs). Technical change had clearly played a major role in the growth of urban agriculture, which was derived from the farmers towards the profit maximising behaviour and encourages them to adopt new cost-saving technologies. However, the farmers could not adopt most of the recent technological change in agriculture, because they had little capital and apply risk-avoiding strategies. They were using improved varieties of seeds, chemical fertilizers, pesticides and micronutrients. They had adopted new technology and practice at a significant rate since the introduction of improved varieties of seeds. This was mainly in the form of increased use of inorganic chemical fertilizers and agrochemicals, and continuous improvement of plant varieties.

Because of the very small land holding size in the study area, most of the farmers were not able to use modern tractors and other mechanic 
implements. Fields was ploughed in a spade-like (Kodalo/Kodali) curved pattern to ensure proper land tillage at all corners. The tillage tool local harrow (Dalletho) was an indigenous harrow with two extra more or less rectangle (wooden plank) pieces of wood attached to both sides of its handle, which is basically used for the levelling and smoothing of land. These tools are always preferred over the one available in the market; probably because of two-fold functions were saving labour and stabilising loose sandy stratum in one action. Almost all farmers have old tools. Most of the old tools were still in use.

Transport was another factor of farming system approach. The horticultural products required rapid transport to the urban markets. Previously, apart from walking/pottering, the main means of transportation in the study area was bicycle. In the past, most of the farmers used bicycle for the sale of their products to the urban centre, but still they were using bicycle as a major means of transportation to sale the products. Bicycle was individual means of transport, but in the collective form, they had used Minibuses or Lorries to carry their products to the market centre.

\section{Access to Indigenous Knowledge}

Pottier (1994) alerts us to the fact that indigenous knowledge is not always equally shared or accessible to all local residents, and that we cannot assume that the knowledge generated by one farmer is the knowledge of all the other farmers, i.e. it is not common property. Rather, access depends on the types of residents (young and old, male and female, powerful and marginalised, and so on) and the types of knowledge. With regard to subsistence farming for food security, upon which most parish residents depend for survival and argued that it is most probable that indigenous knowledge on this topic is fairly equally shared among farmers and labourers, males and females, and across all age groups within the farming system and household structure. However, there was a difference in distribution of labour and responsibility between the sexes and age groups. Given this, it was likely that different gender and age groups had different levels of knowledge based on their areas and levels of responsibility. It was also noted that due to taste preferences and experience elderly residents had almost exclusive knowledge about a few specific traditional vegetables, which were no longer consumed or generally used by the younger parish residents. This knowledge included food preparation and ritual practices. 
Hence finding of this study supports Johan Pottier's contention that indigenous knowledge about a specific topic, such as agriculture or traditional vegetables, is not equally shared among all the people in a specific area. In fact, a careful understanding of indigenous knowledge makes us aware of who has what information and for what purposes (Sillitoe, Bicker \& Pottier, 2002). It also identifies class and other local systems of differentiation and suggests ways of communicating and understanding local differences and similarities. This is important if we are to improve our understanding of local knowledge and enable local people to use it to improve their circumstances.

\section{CONCLUSION}

The total nutrient supply from different sources indicates, not much problem of macronutrients other than boron and zinc. Boron deficiency must be met from other sources than compost, because even the relatively high applications of farmyard manure (FYM) do not contain enough boron. A minor proportion of farmers had also faced zinc deficiency. Farmers were working for a long time to try to sustain the agricultural production through various means such as by increasing compost and farmyard manure by the use household waste, wood dust, other green plants and vegetables, as well as chicken manures and other methodologies. Nevertheless, their knowledge of plant nutrition is also not perfect and that they tend to use fertilizers and "vitamins" (micronutrients or other growth conditioners) at random. Due to limits to the local knowledge regarding vitamin, they did not know what were the contents in the package of so-called vitamins and the use of chemical fertilizers and its quantity. They did not have information and knowledge about nutrient demand by crops, nutrient supply from soil and different inputs. Similarly, they were also not aware about the knowledge on how to measure the demand of vitamins and other nutrients of crops.

As a source of fertilizer, use of both organic and chemical fertilizers had been growing rapidly. Manure, chicken manure and compost were the major sources of organic fertiliser. The local knowledge reflected that chicken manure had more power (shakti/takat) than rest all. However, to some extent they also believed on the cow manure as a source of power for vegetable production. Different micronutrients were also used for the betterment of the vegetable production. There was increasing vegetable production, which was associated with the use of sufficient amount of organic manure, use of different macro and micronutrients. However, the 
adverse effect of excessive use of chemical fertilizers and pesticides was also seen, thus vegetables were not growing properly after the use of high amount of chemical fertilizers and pesticides. Intensive cropping and use of acidifying fertilizers had led to very low $\mathrm{pH}$ values.

\section{REFERENCES}

Aase, T.H. (1997). Interpretation of categories. observation, concept and category (English Translation), in Fossåskaret E., Fuglested O. L., Aase T.H., red.: Metodisk feltarbeid, produsksjon og tolkning av kavalitative data, Universitetsforlaget.

Andersen, P. (2000). Beyond local knowledge and institutional reach: Micronutrients disorders in hill agriculture, paper presented at Regional conference on physical mobility and development in the mountains, Kathmandu, March 15-17.

Bhatta, G. D. (2011). Smallholder peri-urban organic farming in nepal: a comparative analysis of farming systems. Journal of Agriculture, Food Systems and Community Development, 1 (3).

Blaikie, P and Brookfield, H. (1987). Land degradation and society. USA: Methuen and Co.

Blaikie, P.M. and Sadeque, S.Z. (2000). Policy in high places: Environment and development in the Himalayan region. Kathmandu: ICIMOD.

Briggs, J. (2005) The use of indigenous knowledge in development: problems and challenges. Progress in Development Studies 5(2):99-114.

Briggs, J., Badir, M. and Mekki, A.M. (1999). Indigenous knowledge and vegetation use among bedouin in the eastern desert of Egypt. Applied Geography (19) 87-103.

Briggs, J., Pulford, I.D., Badir, M. and Shaheen, A.S. (1998). Indigenous and scientific knowledge: The choice and management of cultivation sites by Bedouin in upper Egypt. Soil and Management. 14, 240245 .

Chambers, R. (1983). Rural development: Putting the last first. Harlow: Longman.

Chaudhary, S.L. and Manandhar R. (1996). Extension of soil fertility and plant nutrition management: DOA's experience. National workshop on soil fertility and plant nutrition management. 19-20 December 1996. Soil Science Division, Nepal Agricultural Research Council (NARC), Nepal. 
Gupta, A. (1987). Technology, power and the state in a complex agricultural society: The green revolution in a North Indian village. Unpublished Dissertation for Ph.D Degree, Stanford University.

Hay, I. (Ed.). (2000). Qualitative research methods in human geography. Meridian: Australian Geographical Perspectives, Oxford University Press.

Hettne, B. (1990). Development theory and the three worlds: Towards an international political economy of development $\left(1^{\text {st }} \mathrm{ed}\right.$.). Longman Science \& Technology.

Hogg, D. (2000). Technological change in agriculture: Locking into genetic uniformity. Hampshire. Houndmills: Macmillan Press.

Lumu R, Katongole C.B., Nambi-Kasozi J, Bareeba F, Presto M, Ivarsson E, and Lindberg J. E. (2013). Indigenous knowledge on the nutritional quality of urban and peri-urban livestock feed resources in Kampala, Uganda. Tropical Animal Health and Production, 45 (7): 1571-1578.

Maddox, G., Giblin, J. and Kimambo, I. N. (Eds.) (1996). Custodians of the land: Ecology and culture in the history of Tanzania. London: James Currey.

Pottier, J. (1994). Agricultural discourses: Farmer experimentation and agricultural extension in Rwanda. In Scoones I. \& Thompson J. (Eds.), Beyond farmer first: rural peoples' knowledge, agricultural research and extension practice. London: Intermediate Technology Publications.

Pretty, J. N. and Chambers, R. (1993). Towards a learning paradigm: New professionalism and institutions for agriculture. IDS Discussion Paper no. 334.

Pretty, J. N. (1995). Regenerating agriculture: Policies and practice for sustainability and self-reliance. London: Earthscan Publications Ltd.

Rappaport. R.A. (1967). Ecology, meaning and religion. Berkeley, California: North Atlantic Books.

Sapkota, K. (2003a). Continuity and change: Knowledge and practice of peri urban agriculture, a case of Manahara low-lying (Phant) area, Madhyapur Thimi Municipality, Bhaktapur District, Nepal. M. Phil thesis, the Department of Geography, University of Bergen, Norway. 
- - (2003b). Gender perspectives on peri-urban agriculture in Nepal. Urban Agriculture Magazine, no. 12, May, 2004. The Netherlands.

- - (2003c). Peri-urban agriculture: The land, farming system and gender. E-conference on optimizing land use in the city area: Access to land use and water adequate norms and regulations, integration in land use planning. Retrieved November 22, 2013 from http://www. ruaf.org/comferencesfr.html

Scoones, I. and Thompson, J. (1993). Challenging the populist perspective: Rural people's knowledge, agricultural research and extension practice. Discussion Paper ( 332) IDS, IIED, England.

Shah, P.B. (1996). Soil fertility and erosion based unsustainability national workshop on concerns in Nepal. Soil fertility and plant nutrition management. Kathmandu: Soil Science Division, NepalAgricultural Research Council (NARC), Department of Agriculture, Fertilizer Advisory, Development and Information, Network for Asia Pacific (FADINAP).

Shiva, V. (1989). Staying alive: Women, ecology and development. Landon: Zed Books.

Sillitoe, P., Bicker, A. and Pottier, J. (2002). Participating in development: Approaches to indigenous knowledge. London and New York: Routledge.

Warren, D. M. (1991). Using indigenous knowledge in agricultural development. World Bank Discussion Papers. Washington, D.C: World Bank.

Yasmeen, G. (2001). Urban agriculture in India: A survey of expertise, capacities and recent experience. New Delhi: India. 